\title{
Validity and reliability of the Greek version of the Diabetic Foot Ulcer Scale - Short Form (DFS-SF)
}

\author{
Nick Kontodimopoulos, ${ }^{1}$ Anastasia Veniou, ${ }^{1}$ Nicholas Tentolouris, ${ }^{2}$ Dimitris Niakas ${ }^{1}$ \\ ${ }^{1}$ Hellenic Open University, Faculty of Social Sciences, Patras, Greece; ${ }^{2}$ First Department of Propedeutic Medicine, National \\ and Kapodistrian University of Athens, Medical School, "Laiko" General Hospital, Athens, Greece
}

\begin{abstract}
OBJECTIVE: Diabetic foot ulcer is a critical and costly complication of diabetes mellitus. The aim of this study was to assess the psychometric properties of the Greek version of the diabetic foot ulcer scale - short form (DFS-SF). DESIGN: A sample of patients with diabetic foot ulcer $(\mathrm{N}=110)$ was surveyed with the DFS-SF and various demographic and disease-related questions. The validated Greek SF-36 instrument was used as a "gold standard" for health-related quality of life comparisons. Hypothesized scale structure, internal consistency reliability (Cronbach's alpha) and various forms of construct validity (convergent, discriminative, concurrent and known-groups) were assessed. RESULTS: Multitrait scaling confirmed the scale structure of the DFS-SF, with 32 excellent item convergence $(100 \%)$ and good discrimination $(84.1 \%)$ rates. Cronbach's alpha was $>\mathbf{0 . 7 0}$ for all scales. Spearman's correlations between similar DFS-SF and SF-36 scales ranged between 0.39-0.79 $(p<0.001)$. Expected interscale correlations and knowngroups comparisons supported construct validity. CONCLUSIONS: The observed psychometric properties of the Greek DFS-SF imply suitability for assessing health-related quality of life in patients with diabetic foot ulcer. Future studies should focus on generalizability of the results, as well as on specific issues such as longitudinal validity and responsiveness.
\end{abstract}

Key words: Diabetic foot ulcer, DFS-SF, Greece, HRQoL, Validity

\section{INTRODUCTION}

Diabetic foot ulcer (DFU) is a critical and costly complication of diabetes mellitus (DM). Approximately $15 \%$ of individuals with DM will have a foot ulcer at some point in their life and the annual

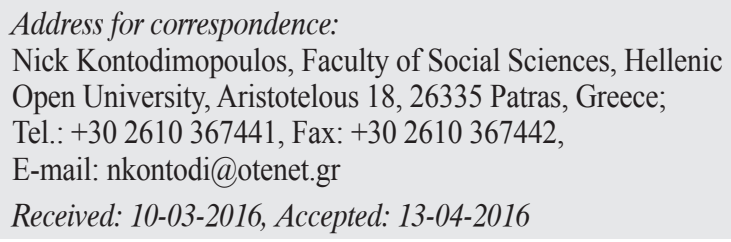

incidence is $2-3 \% .^{1,2}$ Moreover, DFU is becoming a major concern from a quality of life, social and economic standpoint, ${ }^{3}$ with foot problems accounting for up to $15 \%$ of healthcare resources in developed countries and $40 \%$ in developing countries. ${ }^{4}$ Every 30 seconds a lower limb is amputated while $85 \%$ of them is preceded by foot ulcer. ${ }^{5}$ In Greece, a $4.75 \%$ prevalence of DFU has been reported. ${ }^{6}$

In Greece, most diabetic foot patients have neuropathic $(64.9 \%)$ rather than neuroischemic ulcers $(35.1 \%)$, although this is at variance with another study 
reporting $52.1 \%$ neuroischemic, $17.9 \%$ ischemic, and $30 \%$ neuropathic ulceration. ${ }^{8}$ There is evidence of significantly greater age and longer diabetes duration, male preponderance, and increased morbidity among neuroischemic in comparison with neuropathic foot patients and significantly higher frequency of smoking, hypertension, dyslipidemia, retinopathy, nephropathy, and coronary artery disease. ${ }^{7}$ Little is known about the frequency of amputations in Greece. The results of one survey indicated a prevalence of 12.5/1000 patients in 1999, with Greek amputees suffering a mortality of $56 \%$, which represented three times higher compared to the general population. Aboveknee amputations accounted for $18 \%$, below-knee $18 \%$, foot $29 \%$, and toe $35 \%$, and, importantly, $15 \%$ of amputations were bilateral. ${ }^{9}$ Patients with diabetes required a second amputation and a contralateral amputation significantly more frequently than their nondiabetic counterparts. ${ }^{10}$

It has long been established that DFU has a negative impact on patients' health-related quality of life (HRQoL), including physical, social, and psychological aspects. Patients with DFU often have significant physical limitations related to walking and climbing stairs and also experience leg pain and discomfort from the weight of bedding on the ulcer, which may result in sleep disturbance and fatigue. ${ }^{11}$ Moreover, reduced mobility may result in DFU patients finding both physical and personal activities difficult and having to depend on supportive devices or other people for help. ${ }^{12}$ Lack of disabled access and facilities may impede social activity and patients may feel guilty about imposing on the lives of friends or family. ${ }^{13}$ More depression and poorer psychosocial adjustment by DM patients with DFU compared to those without has been shown in early ${ }^{14}$ and recent ${ }^{15}$ studies. In general, adverse psychological effects associated with DFU include a sense of loss of self, social isolation, ${ }^{16}$ loss of self-esteem, fear, anger, helplessness, and depression. ${ }^{11,13,17}$ Patients may worry about the ulcer itself, the potential for new ulcers to develop, and the possibility of amputation. ${ }^{13}$

Due to the high number of comorbidities experienced in DM, a disease-specific quality of life measure is needed to best assess the affect of DFU on HRQoL..$^{18}$ The availability of only limited information on the impact of a foot ulcer on HRQoL in Greece might be partly attributed to the absence of a reliable and valid disease-specific measuring instrument in the Greek language. In an effort to fill this void, the objective of the present study was to assess the psychometric properties of a previously translated version of the diabetic foot ulcer scale - short form (DFS-SF) in a group of Greek patients with DFU.

\section{MATERIALS AND METHODS}

\section{Instruments}

The original diabetic foot ulcer scale (DFS) is a foot ulceration-specific instrument consisting of 58 items grouped into 11 domains: leisure, physical health, daily activities, emotions, noncompliance, family, friends, positive attitude, treatment, satisfaction, and financial. ${ }^{19}$ The DFS-SF, which was employed in this study, is its shorter version and has 29 items on a 5-point likert-type scale which are scored on six scales: leisure (five items), dependence/daily life (five items), negative emotions (six items), physical health (five items), worried about ulcers/feet (four items), and bothered by ulcer care (four items). Domain scores are based on the sum of all items associated with that domain (raw item scores are reverse coded when necessary) and the scores per dimension are transformed to a 0-100 scale, with higher scores corresponding to better HRQoL. The original english language versions of both instruments (i.e. DFS and DFS-SF) have been psychometrically tested and have demonstrated good validity and reliability. ${ }^{19,20}$ The DFS-SF been previously translated into Greek by the Mapi Research Trust (Lyon, France), according to its documented translation methodology. ${ }^{21}$

The SF-36 Health Survey includes eight dimensions: physical functioning, role physical, bodily pain, general health, vitality, social functioning, role emotional, and mental health. ${ }^{22}$ Each dimension is scored on a $0-100$ scale with 0 and 100 corresponding to worst and best health status, respectively ${ }^{23}$ and the eight dimensions can also be summarized in two summary scores of physical and mental health. ${ }^{24}$ The instrument has been translated into Greek and its reliability and validity were established in a representative sample of adults living in the greater Athens area. It was found to have high internal consistency reliability, convergent and discriminative validity and was able to distinguish 
between groups of respondents in the expected manner (known-groups' validity) on the basis of gender, age, and socioeconomic status. ${ }^{25}$ The SF-36 has been shown to discriminate well between perceptions of people with or without one or more chronic diseases ${ }^{26}$ and has previously been used to measure HRQoL in greek studies of people with diabetes ${ }^{27,28}$ and as a "gold standard" for the validation of the greek diabetes treatment satisfaction questionnaire (DTSQ) ${ }^{29}$

\section{Sample and data collection}

The data were collected between November 2013 and March 2014. Eligible participants were adult type 1 or $2 \mathrm{DM}$ patients with diagnosed DFU who were randomly approached during their scheduled visit to the "Laiko" General Hospital in Athens and asked to participate in the study. Non-fluent Greek speakers and subjects incapable of reasoning and decision-making were excluded. Patients with severe comorbidities which could affect HRQoL were also excluded. The survey included the Greek versions of the SF-36 and DFS-SF questionnaires, as well as sociodemographic and other diabetes-specific questions. Completion time was approximately 25 minutes and 110 out of 125 patients visiting the facility during the study period agreed to participate ( $88 \%$ response rate). The Hospital's Review Board granted ethical approval for the study and all participants provided informed consent.

\section{Analysis}

Ulcer severity was assessed in accordance with the University of Texas Wound Classification System of Diabetic Foot Ulcers which evaluates wound depth, the presence of infection, and peripheral arterial occlusive disease in every category of the wound assessment. ${ }^{30}$ Peripheral diabetic neuropathy symptoms and signs were evaluated with the neuropathy symptom score (NSS) and the neuropathy disability score (NDS), which are validated tools with a high predictive value when screening for diabetic polyneuropathy. ${ }^{31,32}$ The NSS is scored on a 0-9 scale and scores of 3-4 are regarded as mild symptoms, 5-6 moderate, and 7-9 severe symptoms. The NDS maximum score is 10 , with a score of 3-5 regarded as evidence of mild neuropathy signs, 6-8 as moderate, and a score of 9-10 as severe signs of neuropathy. ${ }^{33}$
Percentages of floor and ceiling scores were calculated to examine the instrument's ability to distinguish between subjects at the top and bottom ends of the scales. Scale internal consistency reliability was assessed via Cronbach's alpha and the 0.70 standard for group-level comparisons was adopted. ${ }^{34}$ Construct validity was assessed via DFS-SF interscale correlations, and assuming that conceptually related scales would correlate substantially $(>0.40)$, and conversely that scales with less in common would show lower correlations. Spearman's correlations between DFSSF and SF-36 scales were used to assess convergent construct validity. It was hypothesized that scales measuring similar HRQoL dimensions would be strongly $(>0.50)$ correlated. ${ }^{35}$ Based on the literature, such strong correlations might be expected between the DFS-SF's leisure, physical health, dependence/ daily scales and the SF-36's physical functioning, role physical, and bodily pain scales. ${ }^{36}$

Item internal consistency, which is substantial when correlation between an item and its hypothesized scale (corrected for overlap) is $>0.40$, and item discriminant validity, which is successful when correlation between an item and its own scale is significantly higher $(>2$ standard errors) than with other scales ${ }^{37}$ were used to examine the hypothesized scale structure. Each SF36 scale was regressed against the DFS-SF scales to identify aspects of the ulceration-specific instrument more closely linked to general HRQoL. To test knowngroups' validity, the DFS-SF's ability to discriminate between patient groups, which are known to differ on the basis of various clinical variables, was assessed. Differences were examined in terms of DM diagnosis (years), NDS, NSS, presence of DM complications, wound stage and grade, infected ulcer, and clinically significant $(>50 \%)$ vascular stenosis. Throughout the study, probabilities $<0.05$ were regarded as statistically significant. For correlations $>0.7$ and $\mathrm{N}=110$, statistical power was calculated at $>90 \%$. All analyses were performed with SPSS version 21.0.

\section{RESULTS}

Demographic, clinical, and ulcer classification characteristics of the participants $(\mathrm{N}=110)$ are presented in Table 1. The mean age for the entire sample was 60.3 years and the majority were men $(60.9 \%)$. 
Approximately half of the patients were married or living with a partner $(60.9 \%)$, had primary or secondary education $(66.4 \%)$, and were retired $(44.5 \%)$. On average, the patients had been diagnosed with diabetes for 17.4 years and $85.5 \%$ had Type II DM. The majority suffered from a Grade I-B (infected, nonischemic, superficial) or a Grade I-A (non-infected, non-ischemic, superficial) ulcer (31.8\% and $25.5 \%$, respectively). A significant number had at least one DM complication (41.8\%) and one other comorbid condition (49.1\%). Regarding other clinical variables, $69.1 \%$ of the patients had an infected foot ulcer, $38.2 \%$ had $+50 \%$ lower limb vascular stenosis, $12.7 \%$ had undergone a previous limb amputation, and 6.4\% had a history of revascularization. Finally, $40.9 \%$ of the patients showed moderate signs and symptoms of neuropathy (NDS: 6-8 and NSS: 5-6).

Descriptive statistics for DFS-SF scales are presented in Table 2. All data were collected by interview, implying very high response rates throughout and that items and response choices were clear and unambiguous. Mean DFS-SF scores were relatively low in some scales, e.g. "worried about ulcers" (32.6) and "negative emotions" (36.4) accounting for the fairly high floor percentages in the same scales (19.1\% and $10.0 \%$, respectively). On the other hand, ceiling

Table 1. Characteristics of the sample $(n=110)$

\begin{tabular}{|c|c|c|c|}
\hline Demographics & $\mathbf{N}(\%)$ & Clinical & $\mathrm{N}(\%)$ \\
\hline Age $($ mean $\pm \mathrm{SD})$ & $60.3 \pm 12.3$ & Diabetes & \\
\hline Gender male & $67(60.9)$ & Type I & $16(14.5)$ \\
\hline Marital status & & Type II & $94(85.5)$ \\
\hline Married/cohabitation & $67(60.9)$ & Years diagnosed (mean \pm SD) & $17.4 \pm 7.4$ \\
\hline Single/divorced/widowed & $43(39.1)$ & Infected ulcer (yes) & $76(69.1)$ \\
\hline Educational status & & Previous amputation (yes) & $14(12.7)$ \\
\hline Primary/secondary & $73(66.4)$ & Revascularization history (yes) & $7(6.4)$ \\
\hline Tertiary & $37(33.6)$ & $>50 \%$ lower limb vascular stenosis & $42(38.2)$ \\
\hline Work status & & NDS & \\
\hline Employed & $39(35.5)$ & $0-2$ & $18(16.4)$ \\
\hline Unemployed/housekeeping & $22(20.0)$ & $3-5$ & $39(35.4)$ \\
\hline \multirow[t]{2}{*}{ Retired } & $49(44.5)$ & $6-8$ & $45(40.9)$ \\
\hline & & $9-10$ & $8(7.3)$ \\
\hline Classification of ulceration ${ }^{1}$ & & NSS & \\
\hline Grade I-A: non-infected, non-ischemic, superficial & $28(25.5)$ & $0-2$ & $22(20.0)$ \\
\hline Grade I-B: infected, non-ischemic, superficial & $35(31.8)$ & $3-4$ & $34(30.9)$ \\
\hline Grade I-C: ischemic, non-infected, superficial & $2(1.8)$ & $5-6$ & $36(32.7)$ \\
\hline Grade I-D: ischemic and infected, superficial & $5(4.5)$ & $7-9$ & $18(16.4)$ \\
\hline Grade II-A: non-infected, non-ischemic, penetrates to tendon or capsule & $9(8.2)$ & Diabetic complications & \\
\hline Grade II-B: infected, non-ischemic, penetrates to tendon or capsule & $15(13.6)$ & 0 & $31(28.2)$ \\
\hline Grade II-C: ischemic, non-infected, penetrates to tendon or capsule & - & 1 & $46(41.8)$ \\
\hline Grade II-D: ischemic and infected, penetrates to tendon or capsule & $6(5.5)$ & +2 & $33(30.0)$ \\
\hline Grade III-A: non-infected, non-ischemic, penetrates to bone or joint & - & Comorbidities & \\
\hline Grade III-B: infected, non-ischemic, penetrates to bone or joint & $8(7.3)$ & 0 & $33(30.0)$ \\
\hline Grade III-C: ischemic, non-infected, penetrates to bone or joint & - & 1 & $54(49.1)$ \\
\hline Grade III-D: ischemic and infected, penetrates to bone or joint & $2(1.8)$ & +2 & $23(20.9)$ \\
\hline
\end{tabular}

${ }^{1}$ According to University of Texas Wound Classification System of Diabetic Foot Ulcers 
Table 2. Variability and reliability of the DFS-SF and SF-36 scales

\begin{tabular}{lccccccccc}
\hline DFS-SF Scale & Mean & Median & SD & Min & Max & $\begin{array}{c}\text { Floor } \\
\text { \% }\end{array}$ & $\begin{array}{c}\text { Ceiling } \\
\text { \% }\end{array}$ & \multicolumn{2}{c}{ Cronbach's Alpha } \\
\hline Leisure & & & & & & Present study & Bann et al $^{20}$ \\
Physical health & 46.2 & 45.0 & 29.1 & 0 & 100 & 8.2 & 6.4 & 0.93 & 0.90 \\
Dependence/daily life & 59.0 & 60.0 & 24.0 & 0 & 100 & 1.8 & 2.7 & 0.88 & 0.86 \\
Negative emotions & 56.3 & 55.0 & 25.7 & 10 & 100 & 0.9 & 5.5 & 0.87 & 0.84 \\
Worried about ulcers /feet & 36.4 & 29.2 & 26.0 & 0 & 100 & 10.0 & 0.9 & 0.94 & 0.88 \\
Bothered by ulcer care & 47.8 & 25.0 & 28.4 & 0 & 93.8 & 19.1 & 2.7 & 0.91 & 0.93 \\
\hline
\end{tabular}

percentages were generally small throughout. All scales of the greek DFS-SF met the 0.70 internal consistency criterion and Cronbach's alpha indices were comparable to those reported during the development and validation of the initial english version of the instrument. ${ }^{20}$

As seen in the information provided in Table 3, strong interscale correlations between DFS-SF subscales were observed, this possibly being an indication of excessive overlap between what the subscales are attempting to measure, e.g. negative emotions and dependence/daily life $(\mathrm{p}=0.76)$ or leisure and negative emotions $(p=0.73)$. Similar findings have been reported in the validation study of the Chinese DFS$\mathrm{SF} .{ }^{36}$ On the other hand, there is significant evidence of convergent validity from the strong correlations between DFS-SF and SF-36 scales which are intended to measure similar constructs, e.g. physical health and physical functioning $(\mathrm{p}=0.71)$, physical health and vitality $(p=0.79)$, dependence/daily life and physical functioning $(\mathrm{p}=0.71)$, dependence/daily life and vitality $(\mathrm{p}=0.71)$.

Significantly higher item-scale correlations between items and their hypothesized scales than with competing scales were observed (Table 4). The 0.40 item-scale correlation criterion was satisfied, confirming $100 \%$ item convergence in all DFS-SF scales. Accordingly, item discrimination was successful in $122 / 145(84.1 \%)$ of the respective tests. Relatively weaker discriminant validity was recorded in the Dependence/Daily Life and Negative Emotions (76\% and $60 \%$, respectively). Regarding the latter, similar

Table 3. DFS-SF interscale correlations and correlations with SF-36 scales

\begin{tabular}{|c|c|c|c|c|c|c|c|c|c|c|c|c|c|c|}
\hline \multirow[b]{2}{*}{ DFS-SF } & \multicolumn{6}{|c|}{ DFS-SF } & \multicolumn{8}{|c|}{ SF-36 } \\
\hline & 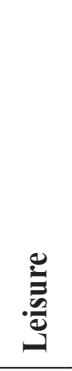 & 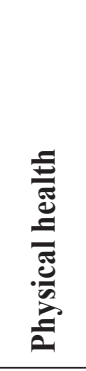 & 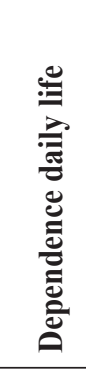 & 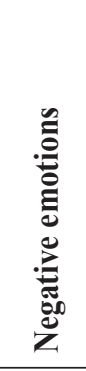 & 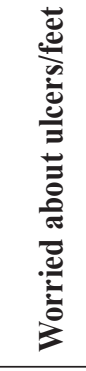 & 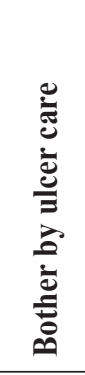 & 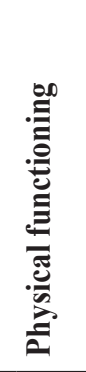 & 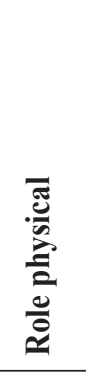 & 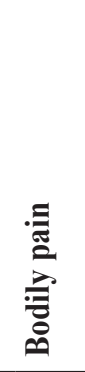 & 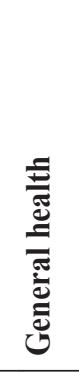 & 吝 & 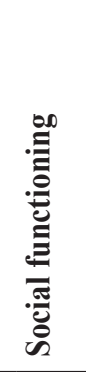 & 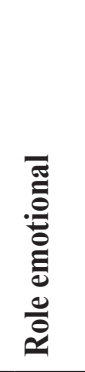 & 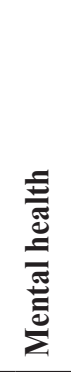 \\
\hline Leisure & 1 & 0.63 & 0.67 & 0.73 & 0.63 & 0.59 & 0.53 & 0.52 & 0.54 & 0.51 & 0.54 & 0.60 & 0.44 & 0.50 \\
\hline Physical health & & 1 & 0.68 & 0.67 & 0.64 & 0.64 & 0.71 & 0.56 & 0.73 & 0.57 & 0.79 & 0.67 & 0.54 & 0.67 \\
\hline Dependence/daily life & & & 1 & 0.76 & 0.65 & 0.68 & 0.71 & 0.63 & 0.48 & 0.57 & 0.71 & 0.63 & 0.54 & 0.56 \\
\hline Negative emotions & & & & 1 & 0.64 & 0.64 & 0.64 & 0.53 & 0.46 & 0.58 & 0.61 & 0.53 & 0.49 & 0.59 \\
\hline Worried about ulcers/feet & & & & & 1 & 0.57 & 0.49 & 0.44 & 0.55 & 0.63 & 0.66 & 0.58 & 0.39 & 0.58 \\
\hline Bother by ulcer care & & & & & & 1 & 0.66 & 0.54 & 0.52 & 0.52 & 0.67 & 0.56 & 0.55 & 0.60 \\
\hline
\end{tabular}

For all correlations $\mathrm{p}<0.001$ according to Spearman's rank test 
Table 4. Summary results of scaling assumption tests

\begin{tabular}{|c|c|c|c|c|c|}
\hline \multirow{2}{*}{ DFS-SF Scale } & \multirow{2}{*}{$\mathbf{N}^{\mathrm{a}}$} & \multicolumn{2}{|c|}{ Item-internal consistency } & \multicolumn{2}{|c|}{ Item-discriminant validity } \\
\hline & & Range of correlations ${ }^{b}$ & \# Success/total ${ }^{\mathrm{c}}$ & Range of correlations ${ }^{\mathrm{d}}$ & \# Success/total ${ }^{\mathrm{e}}$ \\
\hline Leisure & 5 & $0.76-0.86$ & $5 / 5$ & $0.46-0.72$ & $23 / 25$ \\
\hline Physical health & 5 & $0.63-0.77$ & $5 / 5$ & $0.43-0.67$ & $22 / 25$ \\
\hline Dependence/daily life & 5 & $0.60-0.76$ & $5 / 5$ & $0.43-0.73$ & $19 / 25$ \\
\hline Negative emotions & 6 & $0.69-0.89$ & $6 / 6$ & $0.43-0.74$ & $18 / 30$ \\
\hline Worried about ulcers/feet & 4 & $0.70-0.87$ & $4 / 4$ & $0.45-0.70$ & $20 / 20$ \\
\hline Bother by ulcer care & 4 & $0.47-0.72$ & $4 / 4$ & $0.22-0.65$ & $20 / 20$ \\
\hline
\end{tabular}

${ }^{a}$ Number of items and number of item-internal consistency tests per scale

${ }^{b}$ Range of correlations between items and hypothesized scale corrected for overlap

'Number of correlations exceeding the 0.40 standard/total number of correlations

${ }^{\mathrm{d}}$ Range of correlations between items and other scales

eNumber of successful discriminant validity tests/total number of discriminant validity tests

results were observed in the Chinese DFS-SF validation study as well. ${ }^{36}$

The ability of the DFS-SF to capture specific aspects of overall HRQoL is demonstrated by its close relationship with the "gold standard" SF-36. Multiple stepwise linear regression analyses identified the foot ucleration-specific scales that were significant, at the $\mathrm{P}<0.05$ level, in explaining each of the SF-36 scales (Table 5). The analyses demonstrated high explanatory power for all models, ranging from $35.7 \%$ for the Role Emotional scale to $68.1 \%$ for the Vitality scale, implying a close association between the two instruments. Each of the six DFS-SF scales was a significant predictor of at least one SF-36 scale, whereas the DFS-SF Physical Health was a significant predictor of all but one of the SF-36 scales.

Regarding the ability of the DFS-SF instrument to distinguish between groups known to differ in terms of various clinical HRQoL-affecting variables (knowngroups validity), the score differences on all DFS-SF scales, and for all independent variables, were in the expected directions (Table 6). More years with DM, higher NDS and NSS, DM complications, worse wound stage and grade, infected ulcers, and $+50 \%$ vascular stenosis were associated with lower DFS-SF scores on all scales. The only non-significant differences were in respect to DM years on the Leisure scale, classification stage on the dependence and negative emotion scales, and infected ulcer on the latter two scales and on the Leisure scale as well.
Table 5. OLS Regressions

\begin{tabular}{|c|c|c|c|}
\hline SF-36 scales & DFS-SF predictors & p-sig. & $\mathbf{R 2}$ \\
\hline \multirow{3}{*}{ Physical functioning } & Dependence/daily life & 0.001 & 0.605 \\
\hline & Physical health & $<0.001$ & \\
\hline & Bothered & 0.015 & \\
\hline \multirow[t]{2}{*}{ Role physical } & Dependence/daily life & 0.000 & 0.389 \\
\hline & Leisure & 0.035 & \\
\hline Bodily pain & Physical health & $<0.001$ & 0.510 \\
\hline \multirow[t]{3}{*}{ General health } & Worried & 0.009 & 0.437 \\
\hline & Physical health & 0.014 & \\
\hline & Negemotions & 0.028 & \\
\hline \multirow[t]{3}{*}{ Vitality } & Physical health & $<0.001$ & 0.681 \\
\hline & Dependence/daily life & 0.010 & \\
\hline & Bothered & 0.048 & \\
\hline \multirow[t]{2}{*}{ Social functioning } & Physical health & $<0.001$ & 0.500 \\
\hline & Leisure & 0.001 & \\
\hline \multirow[t]{3}{*}{ Role emotional } & Dependence/daily life & 0.079 & 0.357 \\
\hline & Physical health & 0.018 & \\
\hline & Bothered & 0.034 & \\
\hline \multirow[t]{2}{*}{ Mental health } & Physical health & $<0.001$ & 0.507 \\
\hline & Bothered & 0.001 & \\
\hline
\end{tabular}

\section{DISCUSSION}

The DFS-SF has received linguistic validation in Greek according to procedures documented elsewhere. ${ }^{21}$ The aim of this study was to collect evidence of the validity and reliability of this greek version for use in studies with Greek samples. The 
Table 6. DFS-SF scale scores by clinical variables

\begin{tabular}{|c|c|c|c|c|c|c|c|c|c|c|c|c|}
\hline \multirow{3}{*}{ Variable } & \multicolumn{12}{|c|}{ DFS-SF scale } \\
\hline & \multicolumn{2}{|c|}{ Leisure } & \multicolumn{2}{|c|}{ Physical health } & \multicolumn{2}{|c|}{ Dependence } & \multicolumn{2}{|c|}{ Neg. emotions } & \multicolumn{2}{|c|}{ Worried ulcers } & \multicolumn{2}{|c|}{ Bothered } \\
\hline & Mean & $p$-sig. & Mean & $p$-sig. & Mean & $\overline{p \text {-sig. }}$ & Mean & $p$-sig. & Mean & $p$-sig. & Mean & $p$-sig. \\
\hline \multicolumn{13}{|l|}{ DM diagnosis } \\
\hline$\leq 17$ years & 50.9 & \multirow{2}{*}{0.092} & 63.5 & \multirow[b]{2}{*}{0.038} & 62.6 & \multirow[b]{2}{*}{0.011} & 42.7 & \multirow{2}{*}{0.009} & 38.8 & \multirow{2}{*}{0.011} & 54.9 & \multirow[b]{2}{*}{0.001} \\
\hline$>17$ years & 41.5 & & 54.4 & & 50.0 & & 30.2 & & 26.4 & & 40.7 & \\
\hline \multicolumn{13}{|l|}{ NDS } \\
\hline $0-2$ & 65.0 & \multirow{4}{*}{$<0.001$} & 72.2 & \multirow{4}{*}{$<0.001$} & 74.2 & \multirow{4}{*}{$<0.001$} & 49.8 & \multirow{4}{*}{$<0.001$} & 45.1 & \multirow{4}{*}{$<0.001$} & 58.3 & \multirow{4}{*}{$<0.001$} \\
\hline $3-5$ & 54.6 & & 70.4 & & 64.7 & & 45.0 & & 43.8 & & 57.2 & \\
\hline $6-8$ & 36.4 & & 50.0 & & 47.3 & & 28.7 & & 23.1 & & 39.6 & \\
\hline $9-10$ & 18.1 & & 24.4 & & 25.6 & & 8.3 & & 3.1 & & 24.2 & \\
\hline \multicolumn{13}{|l|}{ NSS } \\
\hline $0-2$ & 61.8 & \multirow{4}{*}{$<0.001$} & 72.0 & \multirow{4}{*}{$<0.001$} & 66.4 & \multirow{4}{*}{$<0.001$} & 44.5 & & 42.3 & & 59.1 & \\
\hline $3-4$ & 57.8 & & 69.6 & & 67.9 & & 47.4 & $<0001$ & 42.8 & $<0001$ & 56.1 & $<0001$ \\
\hline $5-6$ & 36.1 & & 50.6 & & 46.7 & & 27.9 & $<0.001$ & 28.0 & $<0.001$ & 36.5 & $<0.001$ \\
\hline $7-9$ & 25.6 & & 40.0 & & 41.4 & & 22.9 & & 10.4 & & 41.0 & \\
\hline DM complicati & & & & & & & & & & & & \\
\hline None & 64.5 & & 69.8 & & 69.5 & & 48.1 & & 40.1 & & 61.1 & \\
\hline One & 42.5 & $<0.001$ & 57.1 & 0.004 & 55.8 & 0.001 & 37.3 & $<0.001$ & 34.9 & 0.007 & 46.3 & $<0.001$ \\
\hline Two or more & 34.2 & & 51.5 & & 44.7 & & 24.2 & & 22.2 & & 37.3 & \\
\hline Grade $^{1}$ & & & & & & & & & & & & \\
\hline I & 53.6 & & 66.4 & & 63.6 & & 42.2 & & 38.7 & & 52.6 & \\
\hline II & 38.7 & $<0.001$ & 50.2 & $<0.001$ & 47.8 & $<0.001$ & 30.8 & $<0.001$ & 26.7 & $<0.001$ & 43.5 & 0.001 \\
\hline III & 17.0 & & 34.0 & & 30.5 & & 12.9 & & 7.5 & & 26.9 & \\
\hline Stage $^{1}$ & & & & & & & & & & & & \\
\hline $\mathrm{A}$ & 54.1 & & 66.2 & & 62.3 & & 41.3 & & 44.9 & & 55.4 & \\
\hline $\mathrm{B} / \mathrm{C}$ & 45.3 & 0.019 & 57.9 & 0.011 & 55.7 & 0.055 & 35.8 & 0.259 & 29.7 & $<0.001$ & 44.7 & 0.035 \\
\hline $\mathrm{D}$ & 28.1 & & 43.5 & & 42.3 & & 25.6 & & 10.6 & & 40.4 & \\
\hline Infected ulcer & & & & & & & & & & & & \\
\hline Yes & 43.2 & 0000 & 55.5 & 0008 & 53.5 & 0080 & 34.2 & 0271 & 26.2 & $<0001$ & 44.2 & 0.014 \\
\hline No & 53.1 & 0.099 & 66.9 & 0.008 & 62.6 & 0.089 & 41.5 & $0.2 / 1$ & 46.7 & $<0.001$ & 55.7 & 0.014 \\
\hline$+50 \%$ vascular & & & & & & & & & & & & \\
\hline Yes & 35.8 & 0.003 & 45.2 & & 48.3 & & 28.7 & & 24.9 & & 39.6 & 0.003 \\
\hline No & 52.6 & 0.003 & & $<0.001$ & 61.3 & 0.015 & & 0.005 & & 0.004 & 52.8 & 0.003 \\
\hline
\end{tabular}

${ }^{1}$ According to university of Texas wound classification system of diabetic foot ulcers NDS: Neuropathy Disability Score; NSS: Neuropathy Symptom Score.

expected added value to the existing international body of knowledge on the subject is the increased confidence in results from studies employing this particular linguistic version of the instrument and the potential for international comparisons. Although generic health status instruments (e.g. SF-36) have shown their validity in Greek samples of people with diabetes $^{27,28}$ and one other diabetes-specific instrument (DTSQ) has been validated, ${ }^{29}$ there are no previous studies measuring the psychometric properties of a DFU-specific instrument in Greece, indicating that an existing void might be needed to be filled.

The overall results for the psychometric properties 
of the DFS-SF instrument were good. The absence of ceiling effects, although a sign of good discriminative ability, might have been expected in this context where an overall poor HRQoL was reported. Following this line of logic, high DFS-SF floor effects might have been anticipated, since there is strong evidence in the literature supporting the negative affect of DFU on health status, ${ }^{38-41}$ but in the end their absence can be taken as evidence that the instrument is sensitive at its lower end. All SF-36 mean scale scores (not shown) were lower than the respective general population scores reported in the instrument validation study. ${ }^{25}$

Scale internal consistency reliability was high (Cronbach's alpha range: 0.79-0.94) and comparable to (or even exceeding) the corresponding coefficients reported in the developmental study of the instrument $^{20}$ and other DFS-SF validations. ${ }^{36}$ Item internal consistency and discriminant validity were also high, providing evidence to confirm the hypothesized scale structure of the DFS-SF and to suggest that the translation of the items and the response choices are appropriate. This is evidence that scale scores derived from the Greek version could contribute to cross-cultural comparisons. It should be noted that the cross-sectional design employed in this study precluded the assessment of responsiveness of the instrument.

Criterion-related construct validity was supported by confirmation of hypothesized strong correlations between DFS-SF and SF-36 scales measuring similar dimensions. Most DFS-SF scales correlated more strongly with SF-36 scales measuring similar HRQoL dimensions than with those measuring less similar ones. On the other hand, the strong interscale correlations between DFS-SF subscales might imply excessive overlap between the constructs being measured, e.g. Negative Emotions and Bothered by Ulcer $(p=0.64)$. This could have been expected because DFUs can deteriorate quickly and limited treatment options can cause patients to worry about further deterioration. ${ }^{11,36}$ Other observed strong interscale correlations might be explained similarly.

The OLS regression models showed relatively high proportions of HRQoL variance explained. The DSFSF Physical Health Scale was a significant predictor of seven SF-36 scales and all DFS-SF scales were significant predictors of at least one SF-36 scale. Although the DFU aspects measured by this instrument are mostly uncontrollable, a systematic approach to even their slight improvement may prove beneficial in terms of HRQoL for this DM population. Portions of variability of each SF-36 scale remained unexplained, since other demographic or health-related variables were not used in the regression models, which indicates the necessity for further research.

Diabetes is a chronic disease with a wide range of associated disabilities and painful conditions which are consistently captured by health status instruments. Overall HRQoL in diabetes is affected by various domains of functioning and well-being, implying the need for a multidimensional measurement approach. ${ }^{42}$ However, it is usually the combined effect of macrovascular and microvascular complications, comorbid conditions, and background demographic, clinical and treatment satisfaction variables which degrade HRQoL and not diabetes per se. ${ }^{43}$ The results of the known-groups comparisons performed here conform to the literature ${ }^{1,12-15,17,27-28,38-41}$ in terms of the score differences and the direction of these differences.

In conclusion, we report that the internal consistency reliability and cross-sectional construct validity of the greek DFS-SF were satisfactorily demonstrated; however, the cross-sectional design of the present study precluded examination of test-retest reliability and responsiveness. Thus, a longitudinal study design could be designed to overcome these limitations as well as to validate the present results. Furthermore, we have not performed a confirmatory factor analysis to directly assess the hypothesized constructs of the greek DFS-SF, as this would have required a much larger sample (approximately ten respondents per item, i.e. at least 290 subjects), which would have proven difficult to access. The instrument was well accepted by the patients and its psychometric properties were similar to those reported in validation studies of other language versions. Overall, the results confirm that the DFS-SF is a reasonable choice for measuring DFU HRQoL in Greece. Providing that future research addresses the aforementioned issues, results from greek studies are anticipated to add to the international body of knowledge in this area of research. 


\section{ACKNOWLEDGEMENTS}

We are grateful to the Mapi Research Trust for granting us permission to use the instrument in our study and to the patients who participated in this study.

\section{REFERENCES}

1. Vileikyte L, 2001 Diabetic foot ulcers: a quality of life issue. Diabetes Metab Res Rev 17: 246-249.

2. Reiber GE, Boyko E, Smith DG, 2005 Lower extremity ulcers and amputations in individuals with diabetes. In: Harris MI, editor. Diabetes in America (2nd ed). National Institutes of Health Publication No. 95-1468.

3. Leung PC, 2007 Diabetic foot ulcers - a comprehensive review. Surgeon 5: 219-231.

4. International Diabetes Federation 2012 The Global Burden. IDF Diabetes Atlas 5th ed.

5. Apelqvist J, Tennvall G, 2005 Counting the costs of the diabetic foot. Diabetes Voice 50 (Special Issue): $8-10$.

6. Manes C, Papazoglou N, Sossidou E, et al, 2004 Prevalence of diabetic foot neuropathy and foot ulceration: identification of potential risk factors. Wounds 14 : 11-15.

7. Doupis J, Grigoropoulou P, Voulgari C, 2008 High rates of co-morbid conditions in patients with type 2 diabetes and foot ulcers. Wounds 20: 132-138.

8. Skoutas D, Papanas N, Georgiadis GS, 2009 Risk factors for ipsilateral re-amputation in patients with prior amputation for diabetic foot lesions. Int J Low Extrem Wounds 8: 69-74.

9. Karagianni D, 2002 Amputations in Diabetic Patients (Population Study) [dissertation]. Alexandroupolis, Greece: Democritus University of Thrace.

10. Papazafiropoulou A, Tentolouris N, Soldatos RP, 2009 Mortality in diabetic and nondiabetic patients after amputations performed from 1996 to 2005 in a tertiary hospital population: a 3 year follow-up study. J Diabetes Complications 23: 7-11.

11. Ribu L, Wahl A, 2004 Living with diabetic foot ulcers: a life of fear, restrictions, and pain. Ostomy Wound Manage 50: 57-67.

12. Ashford RL, McGee P, Kinmond K, 2000 Perception of quality of life by patients with diabetic foot ulcers. Diabet Foot J 3: 150-155.

13. Brod M, 1998 Quality of life issues in patients with diabetes and lower extremity ulcers: patients and caregivers. Qual Life Res 7: 365-372.

14. Carrington AL, Mawdsley SK, Morley M, Kincey J, Boulton AJ, 1996 Psychological status of diabetic people with or without lower limb disability. Diabetes Res Clin Prac 32: 19-25.

15. Fejfarová V, Jirkovská A, Dragomirecká E, et al, 2014 Does the diabetic foot have a significant impact on se- lected psychological or social characteristics of patients with diabetes mellitus? J Diabetes Res 2014: 371938.

16. Kinmond K, McGee P, Gough S, Ashford R, 2003 'Loss of self': a psycho- social study of the quality of life of adults with diabetic ulceration. J Tissue Viability 13: 6-16

17. Goodridge D, Trepman E, Sloan J, et al, 2006 Quality of life of adults with unhealed and healed diabetic foot ulcers. Foot Ankle Int 27: 274-280.

18. Jaska PJ, Mahoney JL, 2010 Quality of Life in patients with diabetic foot ulcers: validation of the Cardiff Wound Impact Schedule in a Canadian population. Int Wound J 7: 502-507.

19. Abetz L, Sutton M, Brady L, McNultly P, Gagnon D, 2002 The Diabetic Foot Ulcer Scale (DFS): a quality of life instrument for use in clinical trials. Practical Diabetes Int 19: 167-175.

20. Bann CM, Fehnel SE, Gagnon DD, 2003 Development and validation of the diabetic foot ulcer scale-short form (DFS-SF). Pharmacoeconomics 21: 1277-1290.

21. Mapi Research Trust 2004 Linguistic Validation Manual for Health Outcome Assessments. Lyon, France: Mapi.

22. Ware JE, Sherbourne CD, 1992 The MOS 36-item ShortForm Health Survey (SF-36). Conceptual framework and item selection. Med Care 30: 473-483.

23. Ware JE, Snow KK, Kosinski M, Gandek B 1993 SF-36 Health survey manual and interpretation guide. Boston, MA: The Health Institute.

24. Ware JE, Kosinski M, Keller SD 1994 SF-36 physical and mental health summary scales: A user's manual. Boston MA: The Health Institute.

25. Pappa E, Kontodimopoulos N, Niakas D, 2005 Validating and norming of the Greek SF-36 Health Survey. Qual Life Res 14: 1433-1438.

26. Alonso J, Ferrer M, Gandek B, et al, 2004 Health-related quality of life associated with chronic conditions in eight countries: Results from the International Quality of Life Assessment (IQOLA) Project. Qual Life Res 13: 283-298.

27. Papadopoulos AA, Kontodimopoulos N, Frydas A, Ikonomakis E, Niakas D, 2007 Predictors of healthrelated quality of life in type II diabetic patients in Greece. BMC Public Health 7: 186.

28. Papadopoulos AA, Kontodimopoulos N, Niakas D 2009 Health related quality of life in type II diabetes patients: Assessing socio-demographic and clinical variables. In: Hoffmann EC, editor. Health-Related Quality of Life. New York: Nova Science.

29. Kontodimopoulos N, Arvanitaki E, Aletras VH, Niakas D, 2012 Psychometric properties of the Greek Diabetes Treatment Satisfaction Questionnaire. Health Qual Life Outcomes 10: 17.

30. Lavery LA, Armstrong DG, Harkless LB, 1996 Classification of diabetic foot wounds. J Foot Ankle Surg 35: 528-531.

31. Young MJ, Boulton AJ, Macleod AF, Williams DR, 
Sonksen PH, 1993 A multicentre study of the prevalence of diabetic peripheral neuropathy in the United Kingdom hospital clinic population. Diabetologia 36: 150-154.

32. Meijer JW, Smit AJ, Sonderen EV, Groothoff JW, Eisma WH, Links TP, 2002 Symptom scoring systems to diagnose distal polyneuropathy in diabetes: the Diabetic Neuropathy Symptom score. Diabet Med 19: 962-965.

33. Alexiadou K, Doupis J, 2012 Management of diabetic foot ulcers. Diabetes Ther 3: 4.

34. Nunnaly JC, Bernstein IR, 1994 Psychometric theory, 3rd ed. New York: McGraw Hill.

35. Cohen J, 1992 A power primer. Psychol Bull 112: 155159.

36. Hui LF, Yee-Tak Fong D, Yam M, Yuk Ip W 2008 Translation and validation of the chinese diabetic foot ulcer scale - short form. Patient 1: 137-145.

37. Ware JE, Gandek B, 1998 Methods for testing data quality, scaling assumptions and reliability: The IQOLA Project Approach. J Clin Epidemiol 51: 945-52.

38. Siersma V, Thorsen H, Holstein PE, et al, 2014 Healthrelated quality of life predicts major amputation and death, but not healing, in people with diabetes presenting with foot ulcers: the Eurodiale study. Diabetes Care 37: 694-700.

39. Yao H, Ting X, Minjie W, et al, 2012 The investigation of demographic characteristics and the health-related quality of life in patients with diabetic foot ulcers at first presentation. Int J Low Extrem Wounds 11: 187193.

40. Sanjari M, Safari S, Shokoohi M, et al, 2011 A crosssectional study in Kerman, Iran, on the effect of diabetic foot ulcer on health-related quality of life. Int J Low Extrem Wounds 10: 200-206.

41. Goodridge D, Trepman E, Embil JM, 2005 Healthrelated quality of life in diabetic patients with foot ulcers: literature review. J Wound Ostomy Continence Nurs 32: 368-377.

42. Rose M, Burkert U, Scholler G, Schirop T, Danzer G, Klapp BF, 1998 Determinants of quality of life of patients with diabetes under intensified insulin therapy. Diabetes Care 21: 1876-85.

43. Rubin RR, Peyrot M, 1999 Quality of life and diabetes. Diabetes Metab Res Re 15: 205-218. 